\title{
Sipuleucel-T in the treatment of prostate cancer: an evidence-based review of its place in therapy
}

This article was published in the following Dove Press journal:

Core Evidence

18 December 2014

Number of times this article has been viewed

\author{
Julie N Graff ${ }^{1,2}$ \\ Erin D Chamberlain ${ }^{3}$ \\ 'Portland VA Medical Center, ${ }^{2}$ Knight \\ Cancer Institute, ${ }^{3}$ Department of \\ Medicine, Oregon Health and Science \\ University, Portland, OR, USA
}

\begin{abstract}
Metastatic castration-resistant prostate cancer is the lethal form of cancer of the prostate. Five new agents that prolong survival in this group have emerged in the past 5 years, and sipuleucel-T is among them. Sipuleucel-T is the only immunotherapy shown to improve survival in prostate cancer. It is currently indicated in asymptomatic or mildly symptomatic patients, as it has never shown a direct cancer effect. This paper describes the process of creating the sipuleucel-T product from the manufacturing and patient aspects. It discusses the four placebo-controlled, randomized clinical trials (RCTs) of sipuleucel-T, focusing on survival and adverse events. There are three RCTs in metastatic castration-resistant prostate cancer, all of which showed improved overall survival without meaningful decreases in symptoms, tumor volumes, or prostate-specific antigen levels. One RCT in castration-sensitive, biochemically relapsed prostate cancer attempted to find a decrease in biochemical failure, but that endpoint was not reached. Adverse events in all four of these studies centered around cytokine release. This paper also reviews a Phase II study of sipuleucel-T given neoadjuvantly that speaks to its mechanism of action. Additionally, there is a registry study of sipuleucel-T that has been used to evaluate immunological parameters of the product in men $\geq 80$ years of age and men who had previously been treated with palliative radiation. Attempts to find early markers of response to sipuleucel-T are described. Further ongoing studies that explore the efficacy of sipuleucel-T in combination with immune checkpoint inhibitors and secondgeneration hormonal therapies that are summarized. Finally, the only published economic analysis of sipuleucel-T is discussed.
\end{abstract}

Keywords: prostate cancer, sipuleucel-T, efficacy, economic analysis

Clinical impact summary for Sipuleucel-T in the treatment of prostate cancer

\begin{tabular}{|c|c|c|}
\hline Outcome measure & Evidence & Implication \\
\hline $\begin{array}{l}\text { Disease-oriented } \\
\text { evidence }\end{array}$ & $\begin{array}{l}\text { - Sipuleucel-T leads to recruitment of } \\
\text { T-cells to the tumor. } \\
\text { - Sipuleucel-T may increase PSA doubling time. }\end{array}$ & $\begin{array}{l}\text { - Basic mechanism of } \\
\text { action. }\end{array}$ \\
\hline $\begin{array}{l}\text { Patient-oriented } \\
\text { evidence }\end{array}$ & $\begin{array}{l}\text { - Sipuleucel-T increases overall survival in } \\
\text { patients with mCRPC. } \\
\text { - Sipuleucel-T does not decrease tumor size } \\
\text { or prolong time to progression. } \\
\text { - Sipuleucel-T may prolong time to use of } \\
\text { opiate pain medications. }\end{array}$ & $\begin{array}{l}\text {-Very important outcome } \\
\text { and led to approval of this } \\
\text { agent. } \\
\text { - Important because it } \\
\text { should not be used in } \\
\text { someone with rapidly } \\
\text { progressing mCRPC. } \\
\text {-Very preliminary finding, but } \\
\text { could suggest some delayed } \\
\text { effect on the disease. }\end{array}$ \\
\hline
\end{tabular}

(Continued)
Correspondence: Julie N Graff PortlandVA Medical Center, 37I0 SW US Veterans Hospital Rd, MC P3CHEMO, Portland, OR 97239, USA

Tel +l 5032208262 ext 55688 Email graffj@ohsu.edu submit your manuscript | www.dovepress.com

Dovepress

http://dx.doi.org/10.2147/CE.S547/2 (c) (i) (5) 2015 Graff and Chamberlain. This work is published by Dove Medical Press Limited, and licensed under Creative Commons Attribution - Non Commercial (unported, v3.0) License. The full terms of the License are available at http://creativecommons.org/licenses/by-nc/3.0/. Non-commercial uses of the work are permitted without any friser permission from Dove Medical Press Limited, provided the work is properly attributed. Permissions beyond the scope of the License are administered by Dove Medical Pres Limited. Information on how to request permission may be found at: http://www.dovepress.com/permissions.php 


\begin{tabular}{|c|c|c|}
\hline $\begin{array}{l}\text { (Continued) } \\
\text { Outcome measure }\end{array}$ & Evidence & Implication \\
\hline Economic evidence & $\begin{array}{l}\text { - A single analysis using the cost } \\
\text { of sipuleucel-T in US dollars }(\$ 140,536) \\
\text { and a gain of } 0.37 \text { quality-adjusted life years } \\
\text { determined that there was } 96.5 \% \text { certainty } \\
\text { it was not cost-effective. }\end{array}$ & $\begin{array}{l}\text { - The current cost to } \\
\text { outcomes ratio seen in } \\
\text { the IMPACT study does } \\
\text { not support the use of } \\
\text { sipuleucel-T. If the price goes } \\
\text { down, or the improvement } \\
\text { in survival goes up, this may } \\
\text { be adjusted. }\end{array}$ \\
\hline
\end{tabular}

\section{Background}

Prostate cancer is the most common cancer affecting men. It is the second leading cause of cancer-related deaths in men, behind lung cancer. In the USA, of the approximately 1.7 million new cancer cases in men and women expected in 2014, roughly 233,000 of these will be prostate cancer. ${ }^{1}$ An estimated 29,480 US men and 70,000 European men will die from prostate cancer in 2014. ${ }^{1,2}$

Metastatic castration-resistant prostate cancer (mCRPC) is prostate cancer that has spread and no longer responds to surgical or medical castration, defined as a serum testosterone $<50 \mathrm{ng} / \mathrm{dL}$. In this setting, hormone therapies that interfere with androgen signaling or further decrease circulating androgens can extend survival and decrease the volume of prostate cancer, both radiographically and biochemically (prostate-specific antigen [PSA]). In 2011, the COU-AA-301 trial of abiraterone with prednisone versus placebo with prednisone in patients with $\mathrm{MCRPC}$ previously treated with docetaxel chemotherapy demonstrated improved overall survival of the abiraterone-containing arm (14.8 months versus 10.9 months; $P<0.001)$ and increased time to PSA progression (10.2 months versus 6.6 months; $P<0.001$ ), plus improvement in progression-free survival (5.6 months versus 3.6 months; $P<0.001$ ) and PSA response rate $(29 \%$ versus $6 \% ; P<0.001)$, defined as a reduction in PSA by at least $50 \%{ }^{3}$ In 2012, the COU-AA-302 study in mCRPC chemotherapy-naïve patients also demonstrated improvement in overall survival and prostate cancer response (updated overall survival 34.7 months on the abiraterone arm versus 30.3 months on the placebo arm; $P=0.0027){ }^{4}$ Radiographic progression-free survival was increased on the abiraterone arm, where the median was not reached in the abiraterone arm versus 8.3 months $(P<0.001)$ on the placebo group. ${ }^{5}$

In 2012, results from the AFFIRM study of enzalutamide versus placebo showed a survival benefit and reduction of disease burden in men with $\mathrm{MCRPC}$ previously treated with docetaxel chemotherapy. ${ }^{6}$ The PREVAIL study, published in
2014, demonstrated improved outcomes in chemotherapynaïve $\mathrm{mCRPC}$, including increased overall survival of 32.4 months in the enzalutamide group versus 30.2 months in the placebo group $(P<0.001)$ and an $81 \%$ reduced risk of radiographic progression on the enzalutamide arm (hazards ratio [HR] 0.19, 95\% confidence interval [CI] 0.15-0.23; $P<0.001)^{7}$

There are two chemotherapy agents that have demonstrated improved survival in mCRPC patients, namely docetaxel and cabazitaxel. In 2004, the TAX327 and SWOG9916 studies showed a survival advantage of docetaxel over mitoxantrone in men with mCRPC. ${ }^{8,9}$ In 2010, the TROPIC study demonstrated a survival advantage of cabazitaxel over mitoxantrone in men previously treated with docetaxel. ${ }^{10}$

Radium-223 is a radiopharmaceutical that has demonstrated improved overall survival relative to placebo, but not improved time to PSA or radiographic progression. ${ }^{11}$ Of note, exclusion criteria included visceral metastatic disease or lymph nodes greater than $3 \mathrm{~cm}$ in the short axis. In this study, overall survival was 14 months in the radium-223 group versus 11.2 months in the placebo group $(P=0.002)$, and there was an increased time to first skeletal-related event in the radium-223 group of 15.6 months and 9.8 months $(P<0.001)$, respectively.

The emergence of five new agents since 2010 that improve survival in mCRPC has changed the way clinicians view mCRPC. The median survival of $\mathrm{mCRPC}$ has shifted from 20 months to longer, although it is difficult to estimate true life expectancy. ${ }^{12}$ This review focuses on the first of the new agents to emerge, ie, sipuleucel-T (Provenge $^{\circledR}$, Dendreon Corporation, Seattle, WA, USA). It describes the treatment process and lays out the clinical trials that led to the approval of this agent in the mCRPC setting. It also describes a fourth randomized clinical trial that took place in the castration-sensitive prostate cancer population as well as ongoing Phase II studies to examine the efficacy of sipuleucel- $T$ in combination with the other agents described above. 


\section{Details of sipuleucel-T treatment}

Sipuleucel-T is an autologous cellular immunotherapy and the first therapeutic cancer vaccine approved by the US Food and Drug Administration (FDA). ${ }^{13}$ To create the vaccine, the patient's dendritic cells are harvested, loaded with a specific antigen ex vivo, and then introduced back into the patient to induce an immune response. More specifically, antigen-presenting cells (APCs) and other peripheral blood mononuclear cells are collected via leukapheresis from the patient's peripheral blood and sent to a central processing facility. There, the APCs are exposed to a recombinant fusion protein that functions as a prostate cancer-associated antigen. This recombinant antigen consists of two key components. The first is prostatic acid phosphatase (PAP). PAP is a phosphatase enzyme expressed in more than $95 \%$ of prostate adenocarcinomas and is highly specific to prostate tissue. ${ }^{14}$ The second key component of the recombinant antigen is the immune cell activator, granulocyte macrophage colony stimulating factor (GM-CSF). The receptor for GM-CSF is expressed broadly on APCs derived from blood and bone marrow. ${ }^{15}$ When bound to the APC, GM-CSF stimulates upregulation of other key immune function molecules, including cytokines and costimulatory molecules. ${ }^{16}$ These two components combine to form a recombinant fusion protein of PAP-GMCSF, known as PA2024. ${ }^{17}$ This recombinant fusion protein is incubated with the patient's resting APCs for 36-48 hours, during which time the APCs digest and display part of the antigen on their cell surface. ${ }^{18}$ This results in APC maturation. This process is done outside of the patient's body to avoid the immunosuppressive environment created by prostate cancer cells inside the body. The matured APCs, known as APC8015, comprise the vaccine, which is suspended in Lactated Ringer's solution and subsequently delivered to the patient for reinfusion. ${ }^{19}$

Although the precise mechanism of action is unknown, sipuleucel- $\mathrm{T}$ is designed to induce a systemic immune response against the patient's prostate cancer cells, which express PAP. The PA2024-loaded APCs make up the active component of sipuleucel-T. T-cells bind the processed recombinant antigen on the surface of the APC. Once bound, the T-cell activates circulating T-cell-mediated destruction of tumor cells by immunogenic cell death. Recently, a multicenter Phase II neoadjuvant trial administering sipuleucel-T to patients with localized prostate cancer demonstrated a new understanding of the drug's mechanism..$^{20}$ This early study suggests both a systemic antigen-specific T-cell response and a local response characterized by recruitment of activated effector T-cells directly to tumor tissue. Another proposed mechanism includes a concept of antigen spreading. Initially, the activated T-cell responds to a specific antigen, in this example PAP, and facilitates death of antigen-exposed cells. However, the release of additional tumor antigens from the lysed cell introduced new antigens for targeting, thus spreading or broadening the antitumor immune response. ${ }^{21}$

Administration of sipuleucel-T requires careful coordination. The patient undergoes three treatment cycles, typically over the course of 4 weeks. Each cycle consists of two visits. Early in the week, the patient undergoes leukapheresis at an approved cell collection center. Cells are sent unfrozen to a central processing facility, matured into the final product, suspended in Lactated Ringer's solution for up to 18 hours, and returned to the patient 3 days later for infusion. This process takes one week. A full treatment consists of three cycles. For the studies that included a control arm (D9901, D9902A, D9902B/ IMPACT, and PROTECT, as described below), the same procedures were followed in the control arm, except that PA2024 was omitted.

\section{Clinical trials in metastatic castration-resistant prostate cancer}

Early evidence of clinical activity for sipuleucel-T was seen in a Phase III trial (D9901) published in 2006. ${ }^{22}$ In this randomized, double-blind, placebo-controlled trial, the immunologic therapy was given to patients with mCRPC. A total of 127 patients were enrolled across 19 centers. Eligible patients had an expected survival of at least 3 months, Eastern Cooperative Oncology Group status of 0 or 1, and positive immunohistochemistry for PAP in at least $25 \%$ of cells. Prior investigational agents were discontinued at least one month before treatment. Participants could not have received more than two lines of chemotherapy for prostate cancer, and the most recent chemotherapy had to be at least 3 months prior to the start of sipuleucel-T. Patients were not permitted to have visceral disease or a history of pathologic fracture in the appendicular skeleton. Radiation therapy had to be completed at least one year prior to treatment. Patients needing concurrent systemic corticosteroids, those who had received prior immunotherapy, and those with pain attributable to malignancy were excluded. Patients were either surgically castrate or continued on gonadal suppression with a luteinizing hormone-releasing hormone agonist throughout the trial. Patients were assigned in a 2:1 ratio to receive sipuleucel-T or placebo. Treatment was given in three separate infusions at weeks 0,2 , and 4 . Patients were 
observed every 8-12 weeks for progression. Using an intention to treat analysis, the median time to progression, as the primary endpoint, was 11.7 weeks in the sipuleucel-T-treated patients and 10.0 weeks in placebo-treated patients, but this was not significant (HR 1.45, 95\% CI 0.99-2.11; $P=0.052$ ). However, the median overall survival was 25.9 months in sipuleucel-T-treated patients compared with 21.4 months for placebo-treated patients, equating to a statistically significant 4.5-month improvement in overall survival (HR 1.7, 95\% CI 1.13-2.56; $P=0.01$ ). Adverse events are described in Table 1.

Prior to analysis of the results from D9901, a second Phase III study of sipuleucel-T versus placebo was started. The D9902A study used the same enrolment criteria and primary outcome pursuant from the FDA requirement that two Phase III studies show efficacy of an agent. ${ }^{23}$ However, results from D9901 returned prior to accrual of D9902A showing that the primary endpoint had not been met. Therefore, D9902A was stopped early. A combined analysis was

Table I Adverse events in sipuleucel-T studies that occurred at least twice as often in the sipuleucel-T arm in at least one study

\begin{tabular}{|c|c|c|c|}
\hline Side effect & Study & $\begin{array}{l}\text { Percentage in } \\
\text { sipuleucel-T } \\
\text { group } \\
\text { (grade } \geq 3 \text { ) }\end{array}$ & $\begin{array}{l}\text { Percentage } \\
\text { in control } \\
\text { group } \\
(\text { grade } \geq 3 \text { ) }\end{array}$ \\
\hline \multirow[t]{3}{*}{ Chills } & IMPACT & $54.1(1.2)$ & $12.5(0)$ \\
\hline & D990I/D9902A & $57.8(4.8)$ & $7.9(0)$ \\
\hline & PROTECT & 44.0 (I.7) & $10.2(0)$ \\
\hline \multirow[t]{3}{*}{ Pyrexia } & IMPACT & $29.3(0.3)$ & | $3.7(1.8)$ \\
\hline & D990I/D9902A & $32.0(2.0)$ & $6.6(0)$ \\
\hline & PROTECT & $36.2(1.7)$ & $1.7(0)$ \\
\hline \multirow[t]{3}{*}{ Headache } & IMPACT & $16.0(0.3)$ & $4.8(0)$ \\
\hline & D990I/D9902A & $19.0(1.4)$ & $6.6(0)$ \\
\hline & PROTECT & $23.3(0.9)$ & $13.6(0)$ \\
\hline \multirow[t]{3}{*}{ Myalgia } & IMPACT & $9.8(0.6)$ & $4.8(0)$ \\
\hline & D990I/D9902A & NR & NR \\
\hline & PROTECT & $21.6(0.9)$ & $8.5(0)$ \\
\hline Influenza-like & IMPACT & $9.8(0)$ & $3.6(0)$ \\
\hline \multirow[t]{2}{*}{ illness } & D990I/D9902A & $N R$ & $N R$ \\
\hline & PROTECT & I3.8(0) & $3.4(0)$ \\
\hline \multirow[t]{3}{*}{ Hypertension } & IMPACT & $7.4(0.6)$ & $3.0(0)$ \\
\hline & D990I/D9902A & $N R$ & $N R$ \\
\hline & PROTECT & $11.2(0)$ & $13.6(0)$ \\
\hline \multicolumn{4}{|c|}{ Adverse events reported in only one study } \\
\hline Pain & PROTECT & $12.9(0)$ & $0(0)$ \\
\hline Groin pain & IMPACT & $5.0(0)$ & $2.4(0)$ \\
\hline Vomiting & D990I/D9902A & $10.9(0.7)$ & $2.6(0)$ \\
\hline Dyspnea & D990I/D9902A & $10.9(3.4)$ & $2.6(1.3)$ \\
\hline Asthenia & D990I/D9902A & $14.3(0)$ & $3.9(0)$ \\
\hline Hyperhidrosis & IMPACT & $5.3(0)$ & $0.6(0)$ \\
\hline
\end{tabular}

Note: D990I and D9902A population data are pooled.

Abbreviations: IMPACT, Immunotherapy for Prostate Adenocarcinoma Treatment; PROTECT, Provenge Treatment and Early Cancer Treatment; NR, not reported. performed using the previous Phase III D9901 trial mentioned above and the D9902A trial with the 98 patients already accrued. Data collected with the cumulative 225 patients demonstrated an improved median survival in those treated with sipuleucel-T of 23.2 months versus 18.9 months in the placebo-treated group, equating to a $33 \%$ reduction in the risk of death (HR 1.5, 95\% CI 1.1-2.05; $P=0.011) .{ }^{23}$ Importantly, there was no improvement in overall survival when just the patients on D9902A were examined.

The primary weakness of the D9901 and D9902A studies is that they did not have overall survival as their primary endpoint, rather it was a secondary endpoint. Their primary endpoint, progression-free survival, was not significantly improved. Furthermore, the D9902A study was terminated early, so the data are not interpretable on their own. Instead, they are pooled with data from the D9901 study. The baseline patient characteristics in D9902A appear worse in the sipuleucel-T group than in the placebo group, as the patients in the sipuleucel-T group had a higher PSA $(61.3 \mathrm{ng} / \mathrm{mL}$ versus $44.0 \mathrm{ng} / \mathrm{mL}$, respectively) and tended to have more bone metastases (more than ten lesions in 50.8\% versus $37.5 \%$, respectively). On the other hand, those in the placebo group were less likely to have low-grade disease (Gleason sum $\leq 7)$ than those in the sipuleucel-T group $(51.5 \%$ versus $68.7 \%$, respectively).

To confirm the observed increase in survival, 512 patients with mCRPC were enrolled in the double-blind, placebocontrolled, multicenter Immunotherapy for Prostate Adenocarcinoma Treatment (IMPACT) trial, also known as D9902B. ${ }^{24}$ Initially eligible patients included those with Eastern Cooperative Oncology Group score of 0 or 1 , any Gleason score, asymptomatic patients, and progressive disease. However, after an amendment, patients with mildly symptomatic disease were included. Tumor PAP expression was not required. Exclusion criteria included visceral metastases, pathologic bone fractures, spinal cord compression, and treatment in the previous month with systemic glucocorticoids, radiation, surgery, or systemic therapy for prostate cancer, with the exception of medical or surgical castration. Patients were randomized in a 2:1 ratio to sipuleucel-T or placebo and received a total of three infusions 2 weeks apart, each 3 days after a leukapheresis procedure. Patients received serial computed tomography scans, nuclear medicine bone scans, and serum PSA measurements for evidence of progression. The results revealed a relative reduction in the risk of death of $22 \%$ for patients treated with sipuleucel-T as compared with placebo $(P=0.03)$. The median survival was 25.8 months in the sipuleucel-T-treated patients versus 21.7 months in the placebo-treated patients, with an 
estimated 4.1-month improvement in overall survival $(P=0.03)$. As in the D9901 and D9902A trials, there was no observed statistically significant difference in time to progression of disease. Adverse events are presented in Table 1. Based on these data, sipuleucel-T was approved by the FDA in $2010 .{ }^{13}$

Huber et al examined unpublished data from the sipuleucel-T trials that were released by the FDA. ${ }^{25}$ Using this information, they wrote a critique of the IMPACT study suggesting that sipuleucel-T was ineffective. They argued that the difference in overall survival on the placebo arm of IMPACT for men aged $<65$ years and $\geq 65$ years was dubious, with median survival of 28.2 months and 17.2 months, respectively. Specifically, they argued that the 17.2-month survival for men aged $\geq 65$ years was much shorter than would be expected. They attempted to find published clinical trials in patients similar to those enrolled in IMPACT. Since the enrolment criteria for IMPACT were fairly restrictive, they were unable to find studies that adequately reflected the IMPACT population, but they found some post hoc analyses where some participants did, namely from the GVAX and TAX327 studies. ${ }^{26,27}$ The subgroups in these studies were similarly asymptomatic or minimally symptomatic, but Huber et al did not subdivide by age. In the placebo group of these subsets, survival was much longer than 17.2 months, namely 27.1 months in the GVAX placebo group and 25.6 months for all minimally symptomatic patients in TAX327. They maintained that survival in men aged $\geq 65$ years in IMPACT was much lower than it should have been, and posited that the control arm could have been harmful to those aged $\geq 65$ years. The authors suggested that patients in the control arms were rendered immunosuppressed by three leukophereses and reinfusion of only a fraction of their mononuclear cells.

The authors of the IMPACT study issued a rebuttal ${ }^{28}$ addressing each of the three points in the paper by Huber et al. They argued that the difference in survival in the placebo group between men aged $<65$ years and those aged $\geq 65$ years is expected. They did not feel that the subgroups analyzed from the GVAX and TAX327 trials were comparable with those of the IMPACT study. With regard to the third point, Kantoff states that leukopheresis removes only a small portion of mononuclear blood cells and that this number should not negatively affect a man's immune function. ${ }^{28}$ They point out that healthy volunteers who underwent serial leukophereses did not have a "meaningful" decrease in their leukocyte values and were able to mount a normal immune response.

In summary, an improvement in the endpoint of overall survival was demonstrated in three separate randomized clinical trials with sipuleucel-T versus control for men with mCRPC. However, there was no improvement in progression of disease. At this time, there are no surrogate endpoints for survival, which makes designing trials of sipuleucel-T challenging (see Tables 2 and 3 for details). Several trials are underway to examine the impact of combining sipuleucel-T with other active agents (Table 4).

\section{Additional endpoints: time to disease-related pain and time to first opioid analgesic}

Small et al examined time to symptomatic progression in the D9901, D9902A, and IMPACT studies in a post hoc fashion using measurements of time to disease-related pain (TDRP) and time to first opioid analgesic (TFOA). ${ }^{29}$ In all three randomized controlled studies of sipuleucel-T versus placebo, patients maintained pain diaries that were collected and reviewed by blinded reviewers. Patients in the D9901 and D9902A studies included only asymptomatic patients and used TDRP as a secondary endpoint. Initially, the IMPACT study included only asymptomatic patients and used TDRP as a coprimary endpoint. However, an amendment expanded inclusion to those with minimally symptomatic disease, which made TDRP incompatible with the study. Symptomatic disease progression was an a priori

Table 2 Endpoints of Phase III studies of sipuleucel-T versus placebo

\begin{tabular}{|c|c|c|c|c|}
\hline & D990 I & D9902A & $\begin{array}{l}\text { IMPACT } \\
\text { Pre-amendment }\end{array}$ & IMPACT post-amendment \\
\hline $\begin{array}{l}\text { Study population } \\
\text { ( } \mathrm{n}=\text { sipuleucel-T/control) }\end{array}$ & $\begin{array}{l}\text { Asymptomatic mCRPC } \\
(n=82 / 45)\end{array}$ & $\begin{array}{l}\text { Asymptomatic mCRPC } \\
(n=65 / 33)\end{array}$ & $\begin{array}{l}\text { Asymptomatic mCRPC } \\
(n=135 / 68)\end{array}$ & $\begin{array}{l}\text { Asymptomatic or minimally } \\
\text { symptomatic mCRPC } \\
(n=206 / 103)\end{array}$ \\
\hline Primary endpoint & Time to progression & Time to progression & $\begin{array}{l}\text { Time to progression and } \\
\text { time to disease-related pain }\end{array}$ & Overall survival \\
\hline Secondary endpoints & $\begin{array}{l}\text { Time to disease-related } \\
\text { pain, overall survival }\end{array}$ & $\begin{array}{l}\text { Time to disease-related } \\
\text { pain, overall survival }\end{array}$ & $\begin{array}{l}\text { Time to use of first opiate } \\
\text { analgesic use }\end{array}$ & Time to disease progression \\
\hline
\end{tabular}

Abbreviations: IMPACT, Immunotherapy for Prostate Adenocarcinoma Treatment; mCRPC, metastatic castration-resistant prostate cancer. 
Table 3 Clinical endpoints used in randomized, placebo-controlled studies of sipuleucel-T

\begin{tabular}{lll}
\hline & Studies & Significant? \\
\hline $\begin{array}{ll}\text { Clinical endpoints } \\
\text { Progression-free }\end{array}$ & IMPACT (primary) & No \\
survival & D990I (secondary) & No \\
& D9902A (secondary) & No \\
& D990I + D9902A & No \\
Overall survival & IMPACT (primary) & Yes \\
& D990I (secondary) & Yes \\
& D9902A (secondary) & No \\
Radiographic & D990I + D9902A & Yes \\
response rates & IMPACT (primary) & No \\
& D990I (secondary) & No \\
& D9902A (secondary) & No \\
Time to biochemical & D990I + D9902A & No \\
failure & PROTECT (primary) & No \\
\hline
\end{tabular}

Abbreviations: IMPACT, Immunotherapy for Prostate Adenocarcinoma Treatment; PROTECT, Provenge Treatment and Early Cancer Treatment.

endpoint in the D9901 and D9902A studies. In fact, pooling these data from the two studies was also prespecified, but the D9902A study was closed early, so did not contribute enough to that dataset. Furthermore, collection of these endpoints ended 4 weeks after subjects experienced progressive disease in the D9901 and D9902A studies. Prior to an amendment, these data were collected in the IMPACT study until disease-related pain occurred. Subjects who had not developed disease-related pain by the time data collection ended were censored from the analysis. Therefore, the majority of patients had their data censored: for TDRP, sipuleucel-T (51.4\%) and control (48.6\%); for TFOA, sipuleucel-T (68.6\%) and control (65.1\%). Despite the high rate of censoring, this analysis revealed that sipuleucel-T prolonged TFOA relative to control, where median TFOA for the sipuleucel-T arm was 12.6 months (95\% CI 9.3, not reached) and the control arm was 9.7 months (95\% CI 6.0, not estimable), (HR $0.755,95 \%$ CI, 0.579-0.985). TDRP was not significantly changed.

\section{Phase IV analyses: PROCEED}

A Phase IV registry (PROCEED) has been established by the manufacturer of sipuleucel-T to examine patient characteristics and product parameters for patients treated with sipuleucel-T. Specific product parameters include total nucleated cell count, antigen-presenting cell (APC) count, and APC activation. APCs are defined as large cells expressing CD54, while activation is a measure of CD54 upregulation and is felt to represent product potency. Using PROCEED, the product parameters were examined in men aged $\geq 80$ years and men previously treated using radiation therapy with palliative intent. ${ }^{30,31}$ For men aged $\geq 80$ years, product parameters were similar to those for men aged $<80$ years. For men treated with palliative radiation therapy, total nucleated cell counts and APC activation were lower than for those who had not received radiation therapy, but APC counts were comparable. These data are exploratory.

\section{Investigations to find markers of response to therapy}

Predictive markers for response to sipuleucel-T are needed. $\mathrm{McNeel}$ et al recently reported that an elevation of eosinophils at 6 weeks after treatment with sipuleucel-T correlates with increased survival. ${ }^{32}$ They used integrated data from 737 patients enrolled in IMPACT, D9901, or D9902A. Of these, 377 patients $(51 \%)$ had a baseline eosinophil count and at least one post-baseline count. Twenty-eight percent of these patients had elevated eosinophil counts during treatment with sipuleucel-T, which was defined as an eosinophil count that was normal at baseline and increased to more than the upper limit of normal at any other time point within weeks $2-16$, or the eosinophil count remained normal at subsequent measurement but had increased within the normal range to the top quartile (calculated to be an increase of $>0.36 \times 10^{3} / \mathrm{mL}$ ) among those measured. In those with eosinophilia, the eosinophilia correlated significantly with the product parameters of APC and total nucleated cell count. On a patient outcome level, eosinophilia correlated positively with prostate cancer-specific survival (HR 0.713, 95\% CI 0.525-0.970, $P=0.031)$. A trend towards improved overall survival with eosinophilia was also detected (HR $0.859,95 \%$ CI $0.563-$ 1.008, $P=0.057$ ).

The phenomenon of antigen spreading involves development of a T-cell response to antigens other than those contained within the vaccine. ${ }^{21}$ Although the only antigen incorporated into sipuleucel-T is PAP, some patients develop antibodies to antigens other than PAP. ${ }^{33}$ Drake et al used samples collected for the IMPACT study to measure post-treatment immunoglobulin levels that could relate to the development of many antigens, not just PAP. ${ }^{33}$ They correlated overall survival with the development of antigen spreading. Using 133 patients (93 from the sipuleucel-T group and 40 from the control group), they found that development of immunity to at least two antigens conferred an improvement in overall survival. GuhaThakura et al found a similar result using data from the ProACT study (NCT00715078). ${ }^{34}$ 
Table 4 Ongoing interventional studies with sipuleucel-T

\begin{tabular}{|c|c|c|c|}
\hline Study & $\mathbf{n}$ & Study design/endpoints & NCT identifier \\
\hline $\begin{array}{l}\text { Sipuleucel-T with or without radiation therapy } \\
\text { in treating patients with hormone-resistant } \\
\text { metastatic prostate cancer }\end{array}$ & 50 & $\begin{array}{l}\text { Phase II randomized study/feasibility (primary) } \\
\text { Immune response and safety (secondary) }\end{array}$ & NCT0I807065 \\
\hline $\begin{array}{l}\text { Radiation therapy in treating patients with } \\
\text { metastatic hormone-resistant prostate cancer } \\
\text { receiving sipuleucel-T }\end{array}$ & 15 & $\begin{array}{l}\text { Single-arm Phase II study } \\
\text { Immune response (primary) } \\
\text { Safety and clinical response (secondary) }\end{array}$ & NCT0I833208 \\
\hline $\begin{array}{l}\text { Sipuleucel-T with or without tasquinimod in } \\
\text { treating patients with metastatic hormone-resistant } \\
\text { prostate cancer }\end{array}$ & 60 & $\begin{array}{l}\text { Phase II randomized study/immune response } \\
\text { and clinical response (primary and secondary) }\end{array}$ & NCT02159950 \\
\hline $\begin{array}{l}\text { Phase II study of sipuleucel-T and indoximod } \\
\text { for patients with refractory metastatic } \\
\text { prostate cancer }\end{array}$ & 50 & $\begin{array}{l}\text { Phase II randomized (sipuleucel- } \mathrm{T}+\text { indoximod } \\
\text { versus indoximod alone) } \\
\text { Immune response (primary) } \\
\text { Clinical response (secondary) }\end{array}$ & NCT0I560923 \\
\hline $\begin{array}{l}\text { Randomized Phase II trial of combining } \\
\text { sipuleucel-T with immediate versus delayed } \\
\text { CTLA-4 blockade for prostate cancer }\end{array}$ & 54 & $\begin{array}{l}\text { Phase II randomized } \\
\text { Immune response and safety (primary) } \\
\text { Clinical response (secondary) }\end{array}$ & NCT0I804465 \\
\hline $\begin{array}{l}\text { Sipuleucel-T, CT-0II, and cyclophosphamide } \\
\text { for advanced prostate cancer }\end{array}$ & 57 & $\begin{array}{l}\text { Phase II randomized - three arms: sipuleucel-T, } \\
\text { sipuleucel-T + CT-0II (PD-I antibody), sipuleucel-T + } \\
\text { CT-0II + cyclophosphamide } \\
\text { Feasibility (primary) } \\
\text { Clinical outcomes (secondary) }\end{array}$ & NCT0I420965 \\
\hline $\begin{array}{l}\text { Provenge with or without PTVG-HP } \\
\text { DNA booster vaccine in prostate cancer }\end{array}$ & 30 & $\begin{array}{l}\text { Phase II randomized to sipuleucel-T with or without } \\
\text { PTVG-HP DNA booster vaccine } \\
\text { Immune responses (primary) } \\
\text { Clinical responses (secondary) }\end{array}$ & NCT0I706458 \\
\hline $\begin{array}{l}\text { Biological therapy with or without vaccine } \\
\text { therapy in treating patients with metastatic } \\
\text { hormone-resistant prostate cancer }\end{array}$ & 80 & $\begin{array}{l}\text { Phase II randomized to sipuleucel-T or sipuleucel-T } \\
\text { followed by glycosylated recombinant human interleukin-7 } \\
\text { Immune response (primary) } \\
\text { Immune responses, safety and clinical response (secondary) }\end{array}$ & NCT0I88I867 \\
\hline
\end{tabular}

Notes: These studies have similar populations, ie, metastatic castration-resistant prostate cancer without immunosuppression. Prior chemotherapy permitted if given over 3 months prior to sipuleucel-T treatment.

\section{Clinical trials in castration-sensitive prostate cancer}

In 2011, Beer et al published the results of the Provenge Treatment and Early Cancer Treatment (PROTECT) study examining sipuleucel-T in biochemically relapsed (BCR) patients. ${ }^{35}$ Patients must have been between 3 months and 10 years of their radical prostatectomy. Any Gleason grade was acceptable provided the biochemical relapse occurred within 2 years of prostatectomy. A higher grade $(\geq 7)$ was required if the relapsed occurred $>2$ years after prostatectomy. Prior luteinizing hormone-releasing hormone agonist therapy, adjuvant or salvage radiation therapy, and nonsteroidal antiandrogen therapy for BCR were permitted provided that the patient did not have a rising PSA while on androgen suppression therapy, ie, castration-resistant disease, and at least 6 months had elapsed since the last effective date of androgen suppression therapy. BCR was defined as a PSA $>3 \mathrm{ng} / \mathrm{mL}$, but not higher than $20 \mathrm{ng} / \mathrm{mL}$. If previous androgen suppression therapy for BCR had been used, the PSA must have been $>3 \mathrm{ng} / \mathrm{mL}$ and $25 \%$ higher than the nadir on androgen suppression therapy at the time of enrolment.

Patients were randomized 2:1 to sipuleucel-T versus control if their PSA decreased to $<1 \mathrm{ng} / \mathrm{dL}$ after 3-4 months of luteinizing hormone-releasing hormone agonist therapy. The intention to treat analysis was based on those patients whose PSA value decreased as defined above and included 117 patients on the sipuleucel-T arm and 59 patients on the control arm. Treatment for the sipuleucel-T patients was as described in the Details of sipuleucel-T treatment section. The primary endpoint of this study was time to biochemical failure, as defined by time to PSA $\geq 3 \mathrm{ng} / \mathrm{mL}$. This study did not require a confirmatory PSA. PSA was checked at screening, week -1 , week 0 (first infusion), weeks 2,13 , and 26 , and every 3 months until development of metastatic disease.

The median time to biochemical failure was 18.0 months in the sipuleucel-T arm versus 15.4 months in the control arm (HR 0.936, 95\% CI 0.637-1.376). A secondary endpoint was the effect of sipuleucel-T on PSA doubling time (PSADT), for which all PSA values from randomization to initiation of 
systemic therapy were used. Since recovery of testosterone takes time, a later analysis excluded PSA values $\geq 90$ days after randomization, and showed an increase of PSADT in the sipuleucel-T group by $34.4 \%$ relative to the control group $(P=0.046)$. When only PSA levels after confirmation of testosterone recovery were used, PSADT was $47.6 \%$ greater in the sipuleucel-T group $(P=0.038)$. Additional analysis confirmed that activation of APC was greater in the sipuleucel-T-treated group after each treatment.

Sipuleucel-T was well tolerated, with no deaths related to treatment. Discontinuations were not reported. As with other studies, adverse events more common in the sipuleucel-T arm were chills, fever, myalgia, influenza-like symptoms, and pain. The adverse event associated with leukopheresis was oral paresthesia (see Table 1 for more details).

The chief weakness of this study is that despite having a PSA-based endpoint, there was no confirmatory PSA result required. A confirmatory PSA would have helped to establish a true PSA response or failure since PSA values can fluctuate. The study was small and may not have been powered to detect a small difference in median time to biochemical failure. A companion publication reviewed the quality of life results. ${ }^{36}$ The instruments used included the Brief Fatigue Inventory, Linear Analog Self-Assessment Scale, Global Rating of Change, and a symptom checklist developed specifically for this study. ${ }^{37-39}$ The first three instruments are prospectively validated. Assessments were made at week -13 and/or -7 (during treatment with androgen suppression therapy or AST), plus at weeks -1, 13, and 26. Importantly, since information regarding quality of life began weeks prior to treatment with sipuleucel-T, scores often reflected treatment with AST rather than treatment with sipuleucel-T. As expected, there was some improvement in quality of life scores once testosterone recovered. There was no difference in quality of life between the sipuleucel-T and control groups, but this analysis was post hoc and not powered for quality of life outcomes.

\section{Study of neoadjuvant sipuleucel-T}

In the NEOadjuvant Active Cellular immunotherapy (NeoACT) study, 42 patients with localized, treatment-naive prostate cancer were enrolled in a study of sipuleucel-T prior to radical prostatectomy. ${ }^{20}$ In this single-arm Phase II study, patients received the usual treatment with sipuleucel$\mathrm{T}$, namely three courses of leukopheresis, treatment of their white cells ex vivo, and reinfusion back into the patient. This study was done to characterize the immune infiltrate in prostate cancer before and after treatment with sipuleucel-T, and not to look at patient-specific outcomes. It was powered to detect a 2-fold increase in CD3 + T-cell count between the pretreatment biopsy and radical prostatectomy tissue.

Of the 42 patients, one never received sipuleucel-T, 38 received all three treatments with sipuleucel-T, and three received only two treatments. Post-radical prostatectomy, three patients withdrew consent and one was lost to follow-up. Therefore, only 37 patients were evaluable.

Investigators examined three types of prostate tissue in the radical prostatectomy specimen, namely benign glands, the tumor interface, and the tumor center. At the tumor interface, they found a more than 3-fold increase in infiltrating CD3+ cells, CD4+ FOXP3- (T helper) cells, and CD8+ T-cells at the tumor interface in radical prostatectomy specimens relative to the pretreatment biopsy tissue (binomial proportions, all $P<0.001$ ). Infiltrating T-cells were mostly activated, as evidenced by PD-1+ and Ki-67+. Interferon-gamma (IFN $\gamma$ ELISPOT) responses to PAP2024 and CD4 T permeation were significantly increased in tumor tissues compared to benign tissue. Compared with the sipuleucel-T group, the control group had no upregulation of T-cell subsets.

Investigators also compared radical prostatectomy specimens from those treated neoadjuvantly using sipuleucel-T with control tissues from patients who had not received any systemic therapy preoperatively and had their radical prostatectomy during the same period as those who did participate in the study. The investigators used Cancer of the Prostate Risk Assessment criteria to determine the distribution of risk in the study participants and chose control samples that mirrored that distribution.

Examination of peripheral blood mononuclear cells revealed a significant change in antigen-specific T-cell circulation at 12 weeks post-radical prostatectomy relative to baseline. Changes in IFN $\gamma$ ELISPOT for PA2024 from baseline to 12 weeks post-radical prostatectomy was also significantly increased, but IFN $\gamma$ ELISPOT for PAP was only significant for baseline to pre-radical prostatectomy.

\section{Safety of sipuleucel-T}

All four randomized clinical trials of sipuleucel-T versus control showed that sipuleucel-T was well tolerated. The adverse events that occurred more frequently in patients on sipuleucel-T are those that involved cytokine release. Table 1 shows the side effects that occurred at least twice as often in the sipuleucel-T arm relative to placebo. None of the studies reported a high rate of patient discontinuation. Grade $\geq 3$ events were rare. 


\section{Economic analysis}

There is one published economic analysis of sipuleucel-T. ${ }^{40}$ Researchers used a Markov model and the results of the IMPACT study. They understood that sipuleucel-T therapy does not impact progression-free survival or lead to a decreased volume of cancer and that the IMPACT study did not measure quality of life. Therefore, their outcomes were survival and death. Using the cost of sipuleucel-T in US dollars $(\$ 140,536)$ and a gain of 0.37 quality-adjusted life years, the analysis determined there was $96.5 \%$ certainty that it was not cost-effective.

This analysis compared sipuleucel-T with docetaxel, which has been shown to be cost-effective. ${ }^{40}$ However, it did not consider the other new therapies, namely enzalutamide, abiraterone, cabazitaxel, and radium-223.

\section{Future directions}

There have been several clinical trials examining the effect of sipuleucel-T in combination with other agents. One randomized Phase II study (NCT01487863) examined the effect of combining abiraterone plus prednisone with sipuleucel-T, concurrently or sequentially. ${ }^{41}$ Patients were randomized 1:1 to sipuleucel-T with up to 26 weeks of abiraterone with prednisone starting one day after the first of three sipuleucel-T infusions or to abiraterone starting 10 weeks after the first of three infusions. There were 31 patients on the first arm and 32 patients on the second arm. Although prednisone can be an immunosuppressant, there were no significant changes in product parameters. Patient outcomes were not revealed in this interim analysis.

Another randomized Phase II study is examining the combination of sipuleucel-T with concurrent or sequential enzalutamide (NCT01981122). Quinn et al presented an abstract describing good sipuleucel-T product parameters produced in men on enzalutamide. ${ }^{42}$ Again, the outcomes of the 22 enrolled patients were not presented.

Finally, there is interest in combining sipuleucel-T with an immune checkpoint inhibitor, such as an antibody to PD-1 or CTLA $-4 .{ }^{43}$ Theoretically, combining an agent that aids in antigen presentation with one that unlocks T-cell function should be clinically active. Studies still enrolling subjects are presented in Table 4.

\section{Conclusion}

Sipuleucel-T studies illuminate the challenges of defining study endpoints for immunotherapeutic agents. Overall survival is a concrete endpoint with clear importance, and treatment with sipuleucel-T has shown significant improvement in overall survival in three randomized clinical trials in mCRPC. However, studies with sipuleucel-T have failed to show improvement in disease-specific realms, namely disease response (PSA or radiographic) and time to progression. While these endpoints do not meet the importance of overall survival, they are important to patients and providers, particularly when the patient's prostate cancer threaten his quality of life. Therefore, patient selection is essential and should follow that of the IMPACT study, where only patients with asymptomatic or minimally symptomatic prostate cancer were enrolled.

\section{Disclosure}

The authors do not have any conflicts of interest to report in this work.

\section{References}

1. Siegel R, Ma J, Zou Z, Jemal A. Cancer statistics, 2014. CA Cancer J Clin. 2014;64(1):9-29.

2. Malvezzi M, Bertuccio P, Levi F, La Vecchia C, Negri E. European cancer mortality predictions for the year 2014. Ann Oncol. 2014;25(8): 1650-1656.

3. de Bono JS, Logothetis CJ, Molina A, et al. Abiraterone and increased survival in metastatic prostate cancer. $N$ Engl J Med. 2011;364(21): 1995-2005.

4. Ryan C, Smith M, Fizazi K, Miller K. Final overall survival (OS) analysis of COU-AA-302, a randomized phase 3 study of abiraterone acetate (AA) in metastatic castration-resistant prostate cancer (mCRPC) patients (pts) without prior chemotherapy. European Society of Medical Oncology Annual Meeting. 2014:Abstract 753O. Available from: file://C:/Users/susan/Downloads/Genitourinary_tumours_prostate_1. pdffile://C:/Users/susan/Downloads/Genitourinary_tumours__prostate_1.pdf. Accessed November 15, 2014.

5. Ryan CJ, Smith MR, de Bono JS, et al. Abiraterone in metastatic prostate cancer without previous chemotherapy. $N$ Engl J Med. 2013;368(2):138-148.

6. Scher HI, Fizazi K, Saad F, et al. Increased survival with enzalutamide in prostate cancer after chemotherapy. $N$ Engl J Med. 2012;367(13): 1187-1197.

7. Beer TM, Armstrong AJ, Rathkopf DE, et al. Enzalutamide in metastatic prostate cancer before chemotherapy. $N$ Engl J Med. 2014;371(5): 424-433.

8. Tannock IF, de Wit R, Berry WR, et al. Docetaxel plus prednisone or mitoxantrone plus prednisone for advanced prostate cancer. $N$ Engl J Med. 2004;351(15):1502-1512.

9. Petrylak DP, Tangen CM, Hussain MH, et al. Docetaxel and estramustine compared with mitoxantrone and prednisone for advanced refractory prostate cancer. $N$ Engl J Med. 2004;351(15):1513-1520.

10. de Bono JS, Oudard S, Ozguroglu M, et al. Prednisone plus cabazitaxel or mitoxantrone for metastatic castration-resistant prostate cancer progressing after docetaxel treatment: a randomised open-label trial. Lancet. 2010;376(9747):1147-1154.

11. Parker C, Nilsson S, Heinrich D, et al. Alpha emitter radium-223 and survival in metastatic prostate cancer. N Engl J Med. 2013;369(3): 213-223.

12. Tangen CM, Hussain MH, Higano CS, et al. Improved overall survival trends of men with newly diagnosed M1 prostate cancer: a SWOG phase III trial experience (S8494, S8894 and S9346). J Urol. 2012;188(4):1164-1169.

13. Dendreon Corporation. Package insert. Provenge ${ }^{\circledR}$ (sipuleucel-T). Seattle, WA, USA: Dendreon Corporation; 2010.

14. Goldstein NS. Immunophenotypic characterization of 225 prostate adenocarcinomas with intermediate or high Gleason scores. Am J Clin Pathol. 2002;117(3):471-477. 
15. Metcalf D. The colony-stimulating factors and cancer. Nat Rev Cancer. 2010;10(6):425-434.

16. Jubinsky PT, Laurie AS, Nathan DG, Yetz-Aldepe J, Sieff CA. Expression and function of the human granulocyte-macrophage colony-stimulating factor receptor alpha subunit. Blood. 1994;84(12):4174-4185.

17. Patel PH, Kockler DR. Sipuleucel-T: a vaccine for metastatic, asymptomatic, androgen-independent prostate cancer. Ann Pharmacother. 2008;42(1):91-98.

18. Bilusic M, Heery C, Madan RA. Immunotherapy in prostate cancer: emerging strategies against a formidable foe. Vaccine. 2011;29(38): 6485-6497.

19. Gomella LG, Gelpi-Hammerschmidt F, Kundavram C. Practical guide to immunotherapy in castration resistant prostate cancer: the use of sipuleucel-T immunotherapy. Can J Urol. 2014;21(2 Suppl 1): 48-56.

20. Fong L, Carroll P, Weinberg V, et al. Activated lymphocyte recruitment into the tumor microenvironment following preoperative sipuleucel-T for localized prostate cancer. J Natl Cancer Inst. 2014;106(11): pii dju268.

21. Kudo-Saito C, Schlom J, Hodge JW. Induction of an antigen cascade by diversified subcutaneous/intratumoral vaccination is associated with antitumor responses. Clin Cancer Res. 2005;11(6):2416-2426.

22. Small EJ, Schellhammer PF, Higano CS, et al. Placebo-controlled phase III trial of immunologic therapy with sipuleucel-T (APC8015) in patients with metastatic, asymptomatic hormone refractory prostate cancer. J Clin Oncol. 2006;24(19):3089-3094.

23. Higano CS, Schellhammer PF, Small EJ, et al. Integrated data from 2 randomized, double-blind, placebo-controlled, phase 3 trials of active cellular immunotherapy with sipuleucel-T in advanced prostate cancer. Cancer. 2009;115(16):3670-3679.

24. Kantoff PW, Higano CS, Shore ND, et al. Sipuleucel-T immunotherapy for castration-resistant prostate cancer. $N$ Engl J Med. 2010;363(5): 411-422.

25. Huber ML, Haynes L, Parker C, Iversen P. Interdisciplinary critique of sipuleucel-T as immunotherapy in castration-resistant prostate cancer. J Natl Cancer Inst. 2012;104(4):273-279.

26. Berthold DR, Pond GR, Roessner M, de Wit R, Eisenberger M, Tannock AI. Treatment of hormone-refractory prostate cancer with docetaxel or mitoxantrone: relationships between prostate-specific antigen, pain, and quality of life response and survival in the TAX-327 study. Clin Cancer Res. 2008;14(9):2763-2767.

27. Higano C, Saad F, Somer B, et al. A phase 3 trial of GVAX immunotherapy for prostate cancer versus docetaxel plus prednisone in asymptomatic, castration-resistant prostate cancer (CRPC). Presented at the 2009 Genitourinary Cancers Symposium. Proc Am Soc Clin Oncol. 2009:Abstr LBA150.

28. Kantoff PW, Higano CS, Small EJ, Whitmore JB, Frohlich MW, Schellhammer PF. Re: interdisciplinary critique of sipuleucel$\mathrm{T}$ as immunotherapy in castration-resistant prostate cancer. J Natl Cancer Inst. 2012;104(14):1107-1109.
29. Small EJ, Higano CS, Kantoff PW, Whitmore JB, Frohlich MW, Petrylak DP. Time to disease-related pain and first opioid use in patients with metastatic castration-resistant prostate cancer treated with sipuleucel-T. Prostate Cancer Prostatic Dis. 2014;17(3):259-264.

30. [No authors listed]. Sipuleucel-T in metastatic castration-resistant prostate cancer (mCRPC) patients $\geq 80$ years-old: data from PROCEED. Clin Adv Hematol Oncol. 2014;12(4 Suppl 11):11.

31. [No authors listed]. Impact of prior radiation treatment (tx) on sipuleucel-T (sip-T) product parameters in PROCEED patients (pts). Clin Adv Hematol Oncol. 2014;12(4 Suppl 11):8.

32. McNeel DG, Gardner TA, Higano CS, et al. A transient increase in eosinophils is associated with prolonged survival in men with metastatic castration-resistant prostate cancer who receive sipuleucel-T. Cancer Immunol Res. 2014;2(10):988-999.

33. Drake C, Fan L, Thakurta D, Stewart F, Kantoff P, Small E. Antigen spread and survival with sipuleucel-T in patients with advanced prostate cancer. J Clin Oncol. 2014;32 Suppl 4:Abstr 88.

34. GuhaThakura D, Fan L, Vu T, Sheikh NA, Trager JB. Induction of antigen spread after sipuleucel-T treatment and its association with improved clinical outcome. J Immounother Cancer. 2013;1 Suppl 1:P101.

35. Beer TM, Bernstein GT, Corman JM, et al. Randomized trial of autologous cellular immunotherapy with sipuleucel-T in androgen-dependent prostate cancer. Clin Cancer Res. 2011;17(13):4558-4567.

36. Beer TM, Schellhammer PF, Corman JM, et al. Quality of life after sipuleucel-T therapy: results from a randomized, double-blind study in patients with androgen-dependent prostate cancer. Urology. 2013;82(2): 410-415.

37. Mendoza TR, Wang XS, Cleeland CS, et al. The rapid assessment of fatigue severity in cancer patients: use of the Brief Fatigue Inventory. Cancer. 1999;85(5):1186-1196.

38. Priestman TJ, Baum M. Evaluation of quality of life in patients receiving treatment for advanced breast cancer. Lancet. 1976;1(7965): 899-900.

39. Jaeschke R, Singer J, Guyatt GH. Measurement of health status. Ascertaining the minimal clinically important difference. Control Clin Trials. 1989;10(4):407-415.

40. Holko P, Kawalec P. Economic evaluation of sipuleucel-T immunotherapy in castration-resistant prostate cancer. Expert Rev Anticancer Ther. 2014;14(1):63-73.

41. Small EJ, Lance RS, Redfem $\mathrm{CH}$, et al. A randomized phase II trial of sipuleucel-T with concurrent or sequential abiraterone acetate (AA) plus prednisone $(\mathrm{P})$ in metastatic castrate resistant prostate cancer (mCRPC). J Clin Oncol. 2013;31 Suppl:Abstr 5047.

42. Quinn DI, Petrylak DP, Pieczonka CM, et al. A randomized phase II, open-label study of sipuleucel-T with concurrent or sequential enzalutamide in metastatic castration-resistant prostate cancer (mCRPC). J Clin Oncol. 2014;32 Suppl:Abstr 16071.

43. Mouraviev V, Mariados N, Albala D, Concepcion RS, et al. The rationale for optimal combination therapy with sipuleucel-T for patients with castration-resistant prostate cancer. Rev Urol. 2014;16(3):122-130.
Core Evidence

\section{Publish your work in this journal}

Core Evidence is an international, peer-reviewed open-access journal evaluating the evidence underlying the potential place in therapy of drugs throughout their development lifecycle from preclinical to postlaunch. The focus of each review is to evaluate the case for a new drug or class in outcome terms in specific indications and patient groups. Submit your manuscript here: http://www.dovepress.com/core-evidence-journal

\section{Dovepress}

The manuscript management system is completely online and includes a very quick and fair peer-review system, which is all easy to use. Visit http://www.dovepress.com/testimonials.php to read real quotes from published authors. 